\title{
Ultrasonik Kaynak Yöntemiyle Birleştirilen Cam Fiber Takviyeli PP Kompozitlerin Birleştirme Mukavemetine Enerji Yönlendirici Türünün Etkisi
}

\author{
${ }^{* 1}$ Hüseyin Uzun ve ${ }^{2}$ Melih Tuyan \\ ${ }^{* 1}$ Sakarya Uygulamalı Bilimler Üniversitesi, Sakarya, Turkey, huzun@sakarya.edu.tr \\ ${ }^{2}$ Alba Plastik San. Ve Tic. A.Ş., Kocaeli, Turkey, melih.tuyan@albaplastik.com.tr
}

\begin{abstract}
Özet
Bu çalışmada, \%30 cam fiber takviyeli polipropilen (PP) kompozit malzemelerin ultrasonik yöntemle birleştirilmesinde enerji yönlendirici türünün ve dizaynının, birleştirme mukavemeti üzerindeki etkisi araştırılmıştır. Bu amaçla, \%30 cam fiber takviyeli polypropylene (PP) kompozitten üretilmiş otomotiv radyatör fan paneli üzerine, yine aynı malzemeden üretilmiş su tankı üst parçası, ultrasonik yöntem kullanılarak birleştirilmiştir. Kaynak işlemi yapılırken, üçgen, kare ve dikdörtgen şekilli olmak üzere üç farklı enerji yönlendiricisi kullanılmıștır. En uygun enerji yönlendirici tür ve ebadını belirlemek amacıyla, maksimum dayanma basıncının belirlenmesinde şişirme testi uygulanmıştır. Deneysel çalışmaların sonucunda, $3 \mathrm{~mm}$ genişliğinde ve $3 \mathrm{~mm}$ derinliğindeki kare şekilli enerji yönlendiricisi kullanılarak yapılan ultrasonik birleştirilen su tankının maksimum dayanma basıncının, üçgen ve dikdörtgen $(3 \times 1.5 \mathrm{~mm})$ şekilli enerji yönlendiricisi kullanılarak birleştirilenlere göre daha yüksek olduğu tespit edilmiştir.
\end{abstract}

Anahtar kelimeler: Cam fiber takviyeli polipropilen (PP) kompozit malzeme, su tanklı radyatör paneli, ultrasonik kaynak yöntemi, enerji yönlendirici dizaynı

\section{Effect of Energy Director Types on Glass Fiber Reinforced PP Ultrasonic Weld Joint Strength}

\begin{abstract}
In present study, ultrasonic welding of similar $30 \%$ glass fiber reinforced Polypropylene (PP) was performed in order to investigate the effect of energy director types on joint strength. For this purpose, a water tank was welded on an auto radiator fan shroud by using the ultrasonic welding technique with two types of energy director, such as triangular and shear joint designs. The blasting test was carried out the water tank jointed with the fan shroud in order to determine the maximum durable pressure. It was evaluated the most suitable energy director type designs. The experimental results reveal that the maximum durable pressure of shear joint design of width of $3 \mathrm{~mm}$ and depth of $3 \mathrm{~mm}$ was higher than that of the triangular joint and shear joint of width of $3 \mathrm{~mm}$ and depth of $1.5 \mathrm{~mm}$.
\end{abstract}

Keywords: Glass fiber reinforced Polypropylene (PP), ultrasonic welding, auto radiator fan shroud with water tank, energy director types

\section{Giriş}

Son yıllarda, cam fiber takviyeli polipropilen (PP) kompozitlerin çeşitli özelliklerinden dolayı otomobil, oyuncak ve tıp sektörlerinde yaygın olarak kullanıldığını görmekteyiz. Bu termoplastik kompozitlerin çekme mukavemeti yüksek, kimyasallara karşı dayanıklı, çeşitli kaynak metotlarıyla

*Corresponding author: Address: Sakarya Uygulamalı Bilimler Üniversitesi, 54187, Sakarya TURKEY. E-mail address: huzun@sakarya.edu.tr, Phone: +902642956489 
birleştirilebilir ve sıcak-soğuk sıvılardan etkilenmeyen özelliklerinden dolayı tercih edildiklerini görüyoruz. Bu nedenle son yıllarda araştırmacıların cam elyaf takviyeli polipropilen (PP) kompozit malzemeler üzerinde yoğunlaştıkları görülmektedir [1-4].

Araştırmacıların, cam fiber takviyeli polipropilen kompozitlerin titreşim kaynağı [5], sürtünme karıştırma kaynağı [6-8], lazer kaynağı ve ultrasonik kaynak teknikleri kullanılarak yapılan birleştirmelerin mekanik özelikleri üzerinde yoğunlaştıkları görülmektedir. Fakat literatürde cam fiber takviyeli polipropilen kompozitlerin ultrasonik kaynak yöntemi ile birleştirilebilirliği ile ilgili çok fazla bilgiye rastlanmamaktadır. Ultrasonik kaynak yönteminde ekipman fiyatlarının nispeten düşük olması, cihazın uzun ömürlü olması, kaynak kalitesinin tekrarlanabilir olması, düşük maliyet sağlaması, temiz kaynak bölgesi oluşturması, hızlı ve seri imalata uygun olması nedenlerinden dolayı, diğer kaynak yöntemlerine göre endüstriyel sektörlerde tercih edilmektedir $[9,10]$.

Otomotiv sektöründe, otomobillerde kullanılan soğutma fanı ile su tankı, tek bir davlumbaz üzerinde olacak şekilde dizayn edilmeye başlanmıştır (Şekil 1). Böylece hacimsel yer kazanımı mümkün olmaktadır. Gerek fan davlumbazı gerekse su tankı, cam fiber takviyeli polipropilen kompozit malzemeden imal edilmektedirler. Aynı zamanda soğutucu fan davlumbazı üzerine enjeksiyyon işlemi esnasında hazırlanmış su tankı alt kısmı üzerine, su tankının üst parçası ultrasonik kaynak yöntemiyle birleştirilmektedir. Ultrasonik kaynak yönteminde, elektrik enerjisinin yüksek frekanslı mekanik hareket (titreşim) enerjisine dönüştürülerek, birleşme arayüzeyinde 1sının meydana gelmesi sağlanır. Bu 1s1 sayesinde de termoplastik kompozit parçaların birleşme yüzeyleri ve enerji yönlendiricileri ergir. Aynı anda tatbik edilen basınç sayesinde de parçalar arasında moleküler bir bağ meydana gelerek, birleştirme işlemi gerçekleşir.

Ultrasonik kaynak yönteminde birleştirme mukavemetinin yüksek olması ve sızdırmazlığın sağlanması açısından, yöntem parametrelerinin (frekans, kaynak zamanı, kuvvet) uygun seçilmesinin yanında, birleştirme dizayn tipinin de oldukça önemli bir rolü vardır. Genelde ultrasonik kaynak işleminde beş faklı birleştirme dizaynı kullanılmaktadır: (1) düz alın tipi birleştirmeler, (2) enerji yönlendirici (enerji yolluk) tipi birleştirmeler, (3) basamak tipi birleştirmeler, (4) dilli veya oluk tipi birleştirmeler ve (5) makaslama tipi birleştirmeler [9, 10]. Enerji yönlendirici tipi birleştirmelerde, ergime sıcaklığına çok daha kısa zamanda ulaşılmasına ve kaynak zamanının azaltılmasına sebep olması nedeniyle, bu tip dizayn formu termoplastik malzemelerin birleştirilmesinde tercih edilmektedir. Enerji yönlendiricisi, birleştirme esnasında "düzgün ve küçük ilk temas alanı" oluşturma şartını yerine getirme açısından, oldukça büyük önem taşır [10]. Enerji yönlendiricisinin şekil ve boyutu da birleştirme kalitesini etkileyen diğer önemli bir faktördür.

$\mathrm{Bu}$ çalışmada, üçgen, kare ve dikdörtgen olmak üzere üç farklı geometrik şekilde enerji yönlendirici tipi kullanılarak, soğutucu fan davlumbazındaki su tankı alt kısmı üzerine, su tankının üst parçası, ultrasonik kaynak yöntemiyle birleştirilmiştir. Birleştirilen ürünlere patlama testi uygulanarak, hangi enerji yönlendirici dizaynının, birleştirme mukavemeti açısından daha yüksek dayanma basıncı göstereceği tespit edilmeye çalışılmıştır. 


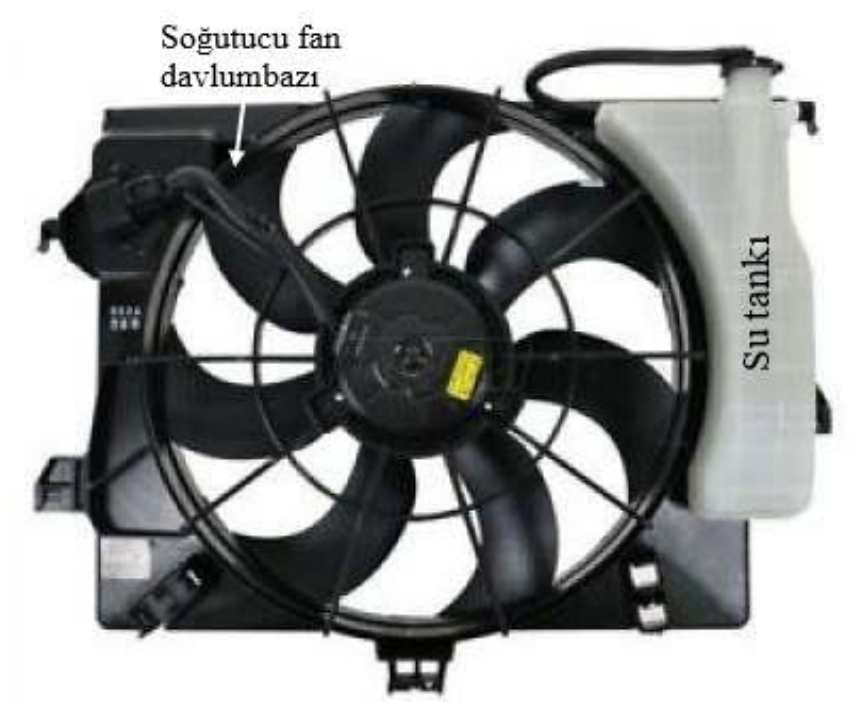

Şekil 1. Soğutucu fan davlumbazı ile su tankının kombine edilmiş dizaynı

\section{Deneysel Çalışmalar}

Deneysel çalışmada kullanılacak ürünü imal etmek amacıyla, soğutucu fan davlumbazı üzerindeki su tankı alt kısmı üzerine, su tankının üst parçası, ultrasonik kaynak yöntemi kullanılarak birleştirilmiştir. Soğutucu fan davlumbazı, plastik enjeksiyon yöntemi kullanılarak, ticari adı HG43HL PP \%30 GF olan \%30 cam fiber takviyeli polipropilen (PP) kompozit malzemeden üretilmiştir. Aynı şekilde su tankını oluşturacak üst parça da ticari adı HG43MC PP \%30 GF olan \%30 cam fiber takviyeli polipropilen (PP) kompozit malzemeden plastik enjeksiyon yöntemi kullanılarak üretilmiştir. Her iki kompozit malzemenin mekanik özellikleri Tablo 1'de verilmiştir. Birleştirme işleminde yeni yenil kaynak yöntemlerinden birisi olan ultrasonik kaynak yöntemi kullanılmıştır. Kaynak işlemi, DAEYOUNG marka ultrasonik kaynak cihazı kullanılarak gerçekleştirilmiştir. Şekil 2'de soğutucu fan davlumbazı üzerindeki su tankı alt kısmı gösterilmektedir. Şekil 3'de de birleştirilecek olan su tankı üst kısmı gösterilmektedir. Ultrasonik birleştirme işleminde, kaynak parametreleri sabit tutularak üçgen, kare ve dikdörtgen geometrik şekillerine sahip üç farklı enerji yönlendirici tasarımına sahip ürünler kullanılmıştır. Tablo 2'de kullanılan ultrasonik kaynak parametreleri verilmiştir.

Tablo 1. Soğutucu fan davlumbazı ve su tankı üst parçasının imal edildiği kompozit malzeme özellikleri

\begin{tabular}{|c|c|c|c|c|c|c|}
\hline Malzeme & Kullanım yeri & $\begin{array}{c}\text { Çekme } \\
\text { Mukavemeti } \\
\text { (MPa) }\end{array}$ & $\begin{array}{c}\% \\
\text { Uzama }\end{array}$ & $\begin{array}{c}\text { Eğme } \\
\text { Mukavemeti } \\
(\mathrm{MPa})\end{array}$ & $\begin{array}{l}\text { Ergime } \\
\text { Sicaklığ } 1 \\
\left({ }^{\circ} \mathrm{C}\right)\end{array}$ & $\begin{array}{c}\text { Rockwell } \\
\text { sertlik değeri }\end{array}$ \\
\hline $\begin{array}{l}H G 43 M C P P \\
\% 30 G F\end{array}$ & Su tank1 üst k1sm1 & 76 & $4-5$ & 117 & $191-232$ & 105 \\
\hline $\begin{array}{l}H G 43 H L P P \\
\% 30 G F\end{array}$ & $\begin{array}{l}\text { Soğutucu fan } \\
\text { davlumbazındaki su } \\
\text { tank1 alt kısmı }\end{array}$ & 80 & 4 & 119 & $191-232$ & 105 \\
\hline
\end{tabular}


Şekil 4 (a)'da görüldüğü gibi kare formundaki enerji yönlendiricinin genişliği $3 \mathrm{~mm}$ ve derinliği 3 mm olarak seçilmiştir. Dikdörtgen enerji yönlendiricinin genişliği $3 \mathrm{~mm}$ ve derinliği $1.5 \mathrm{~mm}$ olarak tasarlanmıştır (Şekil 4 (b)). Üçgen enerji yönlendiricinin ise taban genişliği $3 \mathrm{~mm}$ ve üçgenin derinliği ise $1.5 \mathrm{~mm}$ olarak tasarlanmıştır (Şekil 4 (c)). Birleştirilecek yüzeylerin genişliği 10 mm'dir. Kare, dikdörtgen ve üçgen şekilli formlar, CNC tezgâhında hassas ve yüksek hız takımı ile işlenerek verilmiştir. Kare, dikdörtgen ve üçgen şekilli forma sahip birleştirme yüzeyli ürünlerden üçer adet ürün imal edilmiş ve teste tabi tutulmuştur. Ultrasonik birleştirme sonucu üretilen su tankları, önce sızdırmazlık testine tabi tutulmuşlardır. S1zdırmazlık testinden geçen ürünler, özel olarak tasarlanmış patlatma test cihazında patlatma testine tabi tutularak, üç farklı enerji yönlendiricisi kullanılarak birleştirilen ürünlerin hangi kuvvet değerlerinde patladıkları tespit edilmiştir. Elde edilen sonuçlara göre hangi enerji yönlendirici tasarımının daha dayanıklı birleştirme mukavemeti sağladığı değerlendirilmiştir.

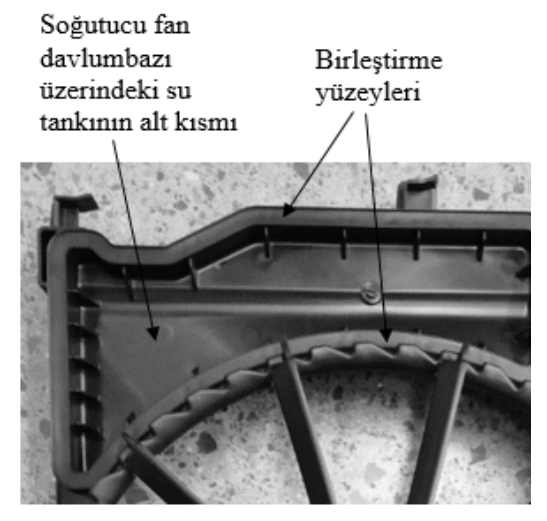

Şekil 2. Soğutucu fan davlumbazı üzerindeki su tankı alt kısmının görünümü

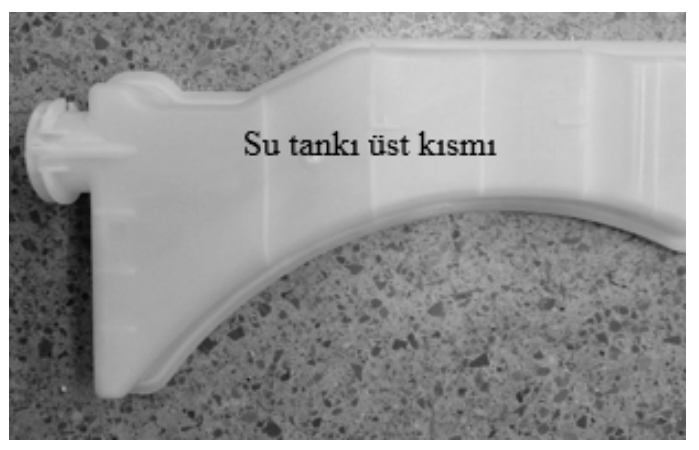

Şekil 3. Su tankı üst kısmının görünümü

Tablo 2. Ultrasonik kaynak parametreleri

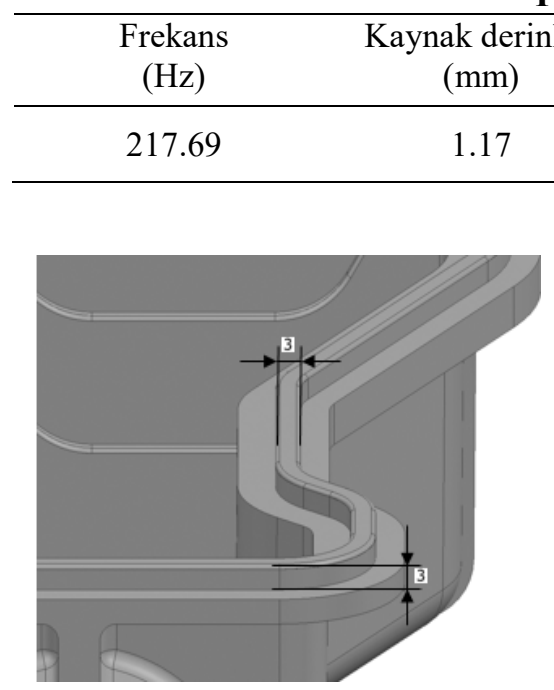

(a)

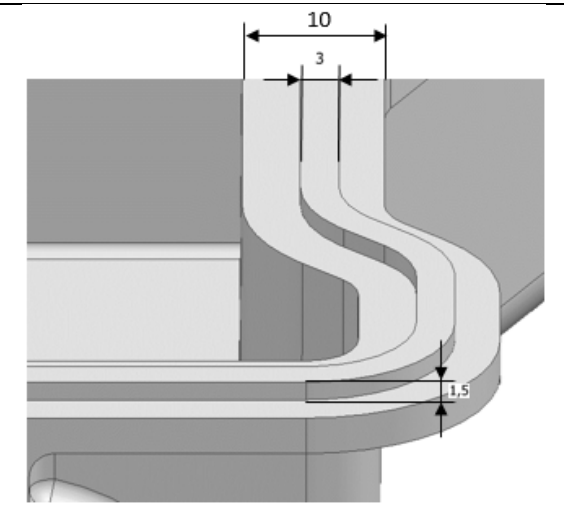

(b)

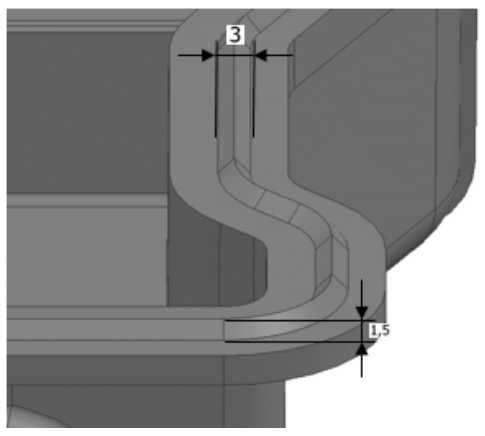

(c)

Şekil 4. Ultrasonik kaynak işleminde kullanılan enerji yönlendirici tasarımları (a) Kare enerji yönlendirici formu (b) Dikdörtgen enerji yönlendirici formu (c) Üçgen enerji yönlendirici formu 


\section{Sonuçlar ve İrdeleme}

\subsection{Makro Inceleme}

Ultrasonik kaynak tekniği ile birleştirilen soğutucu fan davlumbazındaki su tankı alt kısmıyla su tankı üst kısmının birleştirilmesi sonucu meydana gelen ürün Şekil 5'de gösterilmektedir. Fotoğrafta da görüleceği gibi, birleştirme işlemi başarıyla gerçekleşmiştir. Kare, dikdörtgen ve üçgen enerji yönlendiricilerine sahip her üç dizayn şeklinde de birleştirme işlemi başarıyla gerçekleşmiş̧ir. Birleştirme işleminin başarısı, kullanılan ultrasonik kaynak parametrelerinin uygunluğunu göstermektedir. Birleştirilen ürünün kaynak bölgesinin kesit alanı görülecek şekilde kesilmiştir. Şekil 6'da kare enerji yönlendiriciye sahip birleştirme bölgesinin kaynak işlemi sonrası kesit alanı gösterilmektedir. Şekil 6'da su tankının alt kısmı ile üst kısmı birbirini tutacak şekilde kaynaklanmış olduğu görülmektedir. Kaynak bölgesinde herhangi bir kaynak hatasına rastlanmamıştır. Kaynak bölgesinde aşırı malzeme taşması, meydana gelmemiştir. Temiz bir yüzeye sahip kaynak işlemi gerçekleşmiştir.

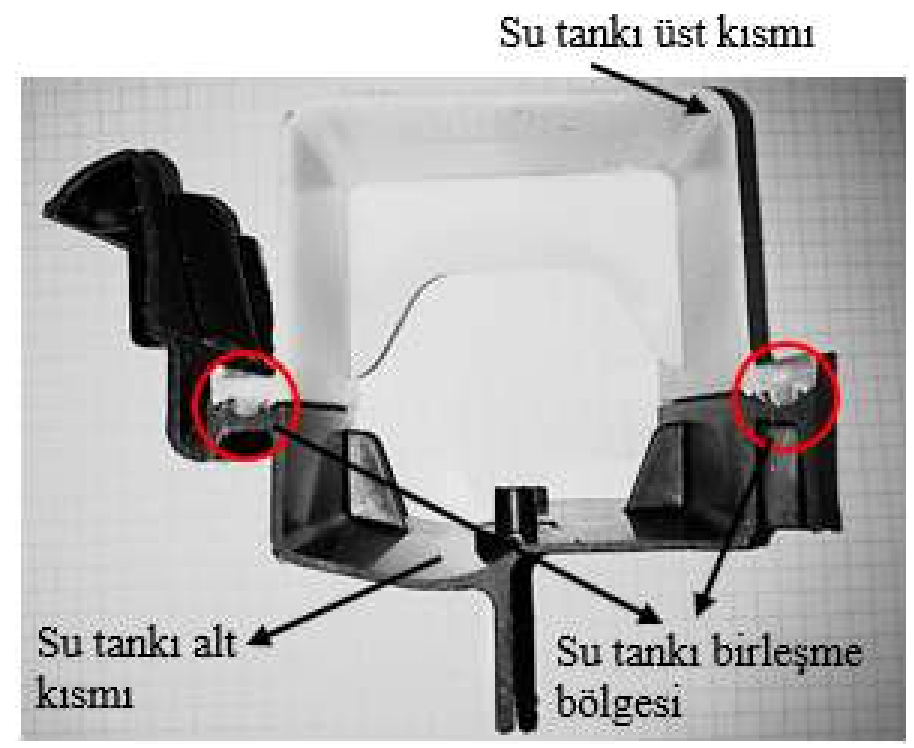

Şekil 5. Soğutucu fan davlumbazındaki su tankı alt kısmıyla su tankı üst kısmının birleştirildiği

\subsection{Patlama Test Sonucu}

Kare, dikdörtgen ve üçgen enerji yönlendiricilerine sahip ürünler, ultrasonik kaynak işlemi sonrası sızdırmazlık testine tabi tutulmuşlardır. Her üç üründe de herhangi bir sızıntıya rastlanmamıştır. Sızdırma testi sonrası her bir su tankına patlama testi uygulanmıştır. Elde edilen maksimum patlama basınçları Tablo 4'te verilmiş̧ir. Her üç enerji yönlendirici formuna sahip birleştirilen ürünlerden, üçer tane ürün üretilmiş ve patlama basınçları tespit edilmiştir. 


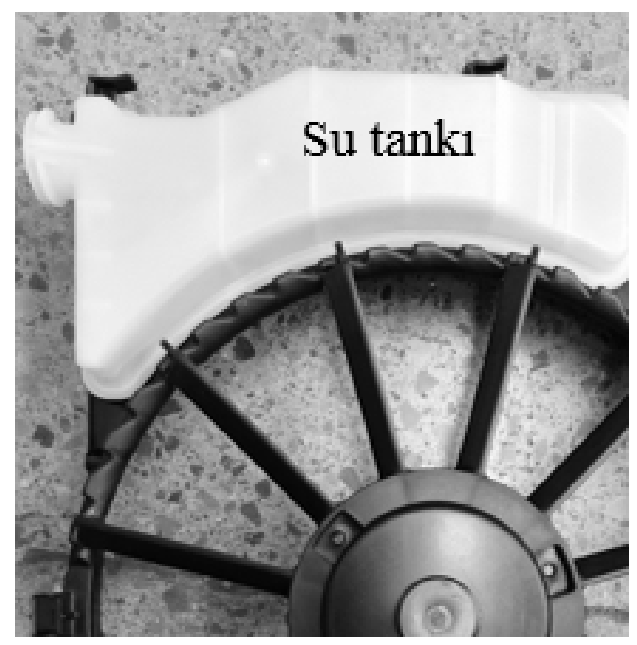

Şekil 6. Kare enerji yönlendiricili birleştirme yüzeylerini sahip ürünün, kaynak işlemi sonrası kesit alanı

Tablo 4. Enerji yönlendirici türüne göre elde edilen maksimum patlama basınç değerleri

\begin{tabular}{lc}
\hline Enerji yönlendirici türüne göre ürünün adı & Maksimum Patlama Basıncı (MPa) \\
\hline Kare enerji yönlendirici birleştirme yüzeylerine sahip ürün & $165 \pm 1$ \\
Dikdörtgen enerji yönlendirici birleştirme yüzeylerine sahip ürün & $125 \pm 1$ \\
Üçgen enerji yönlendirici birleştirme yüzeylerine sahip ürün & $113 \pm 1$ \\
\hline
\end{tabular}

Yapılan patlama deneyi sonucunda, en yüksek patlama basıncı (165 \pm 1$)$, kare enerji yönlendirici birleştirme yüzeylerine sahip ürünlerde tespit edilmiş̧ir. En düşük patlama basıncı $(113 \pm 1)$ ise üçgen enerji yönlendirici birleştirme yüzeylerine sahip ürünlerde bulunmuştur. Kare enerji yönlendiricinin kesit alanı $9 \mathrm{~mm}^{2}$ olması nedeniyle, birleştirme yüzeylerini malzeme daha iyi doldurmuş ve en yüksek patlama basıncı değerini vermiştir. Dikdörtgen enerji yönlendiricinin kesit alanı $4.5 \mathrm{~mm}^{2}$ olması nedeniyle, birleştirme yüzeylerini malzeme daha az doldurmuş ve orta düzeyde patlama basıncı değerine ulaşılmıştır. Üçgen enerji yönlendiricinin kesit alanı ise 2.25 $\mathrm{mm}^{2}$ olması nedeniyle, birleştirme yüzeylerini malzeme çok daha az doldurmuş ve en düşük düzeyde patlama basıncı değerine ulaşılmıştır. Yarı kristalin malzeme olan PP matriks malzemesinin ultrasonik enerji yayılımı zayıftır. O nedenle kaynak Horn'unun (titreşimi direkt parçaya yansıtan ultrasonik kaynak takımı) mümkün olduğunca birleşme bölgesine yakın tutulması önerilir. Böylece kaynak süresi azalır ve daha düşük basınç değerlerinde birleştirme işlemi gerçekleştirilir.

Enerji yönlendiricisinin amacı, en uçtaki ultrasonik enerjiye odaklanmaktır. Böylece 1sının daha hızlı yükselmesi sağlanır. Termoplastik malzemelerde üçgen kesitli enerji yönlendirici kullanıldığında bu durumun daha iyi sağlanmakta olduğu ifade edilmektedir [11]. Fakat bu çalışmamız, cam elyaf takviyeli politilen kompozit malzemelerde üçgen kesitli enerji 
yönlendiricileri, kare kesitli enerji yönlendiricilerinden daha düşük verime sahip olduğunu göstermektedir. Sonuç olarak, bu çalışmada deneysel amaç için üretilen ürünlerin birleştirilmesinde Tablo 2'de verilen ultrasonik kaynak parametreleri kullanılarak yapılan kaynak işleminde, en ideal enerji yönlendirici form şeklinin, $3 \mathrm{~mm}$ genişliğe ve $3 \mathrm{~mm}$ derinliğe sahip kare formu olduğu tespit edilmiştir. Nitekim en yüksek patlama basınç değeri de kare dizayn formundaki üründen alınmıştır.

\section{Sonuçlar}

$\mathrm{Bu}$ çalışmada, üçgen, kare ve dikdörtgen olmak üzere üç farklı geometrik şekilde enerji yönlendirici tipi kullanılarak, soğutucu fan davlumbazındaki su tankı alt kısmı üzerine, su tankının üst parçası, ultrasonik kaynak yöntemiyle başarıyla birleştirilmiştir. He üç enerji yönlendirici dizaynının hangisinin daha yüksek dayanma basıncı göstereceğinin tespit edilmesi amacıyla ilgili araştırmadan elde edilen genel sonuçlar aşă̆ıda verilmiştir.

1. \%30 cam fiber takviyeli polipropilen (PP) kompozit malzemelerin ultrasonik kaynak yöntemiyle enerji yönlendiricisi kullanılarak birleştirilmesi mümkündür. Frekans değeri $217.69 \mathrm{~Hz}$, kaynak süresi 7.19 saniye, çevrim süresi 28.79 saniye ve uygulanan kuvveti 700 kgf olan ultrasonik kaynak parametrelerinin kullanıldığ 1 kaynak işleminde, en ideal enerji yönlendirici form şeklinin, $3 \mathrm{~mm}$ genişliğe ve $3 \mathrm{~mm}$ derinliğe sahip kare formu olduğu tespit edilmiştir.

2. Üçgen şekilli enerji yönlendiricinin ise hem düşük patlama basınç değeri vermesinden hem de kalıba işleme ilave maliyetinin fazla olmasından dolayı uygun bir enerji yönlendiricisi olmadığı belirlenmiştir.

\section{Teşekkür}

Bu çalışmada emeği geçen, Alba Plastik San. Ve Tic. A.Ş yönetici ve çalışanlarına teşekkür ederim.

\section{Kaynaklar}

[1] Thomason, J., Micromechanical parameters from macromechanical measurements on glass reinforced polypropylene, Composites Sci. and Tech., 2002;62, 10;1455-1468.

[2] Vina, J., Arguelles, A. and Canteli, A., Influence of temperature on the fatigue behaviour of glass fibre reinforced polypropylene, Strain, 2011; 47, 3; 222-226.

[3] Seo, Y., Kim, J., Kim, K.U. and Kim, Y.C., Study of the crystallization behaviors of polypropylene and maleic anhydride grafted polypropylene, Polymer, 2000; 41, 7; 2639-2646.

[4] Hamada, H., Fujihara, K. and Harada, A., The influence of sizing conditions on bending properties of continuous glass fiber reinforced polypropylene composites, Comp.Part A:Applied Sci. and Manu., 2000; 31, 9; 979-990. 
[5] Dai, X. and Bates, P., Mechanical properties of vibration welded short-and long-glass-fiberreinforced polypropylene, Com. Part A: Applied Sci. and Manu., 2008; 39, 7; 1159-1166.

[6] Payganeh, G., Arab, N.M., Asl, Y.D., Ghasemi, F. And Boroujeni, M.S., Effects of friction stir welding process parameters on appearance and strength of polypropylene composite welds, Inter. Journal of the Physical Sci.s, 2011; 6,19; 4595-4601.

[7] Ahmadi, H., Experimental analysis of effects of FSW parameters on mechanical properties of PP composites, M.S Dissertation, Tarbiat Dabir University of Shahid Rajaee, (1391)- in Persian.

[8] Strand, S.R., Effects of Friction Stir Welding on Polymer Microstructure, Master of Science Thesis, Brigham Young University, Mechanical Engineering Department, 2004.

[9] Taş Y., Termoplastiklerin, Birleştirilmesinde Kullanılan Ultrasonik Kaynak Yönteminde Kaynak kalitesini etkileyen Parametrelerin İncelenmesi, Yüksek L. Tezi, İTÜ, Ocak 2008, İstanbul.

[10] Ay İ., ve Sakin R., Ultrasonik Yöntemle Plastiklerin Kaynağı, PAGEV Plastik Dergisi, KasımAralık 2005; 94-1008.

[11] https://www.twi-global.com/technical-knowledge, Ultrasonic welding of injection moulded components - Part 2. Component design and weld parameters, 2018. 